\title{
Assessment of energy efficiency of application heat-insulating paint for the needs of district heat supply systems
}

\author{
Mikhail Pavlov ${ }^{1, *}$, Denis Karpov ${ }^{1}$, Irina Akhmetova ${ }^{2}$ and Nikolay Monarkin ${ }^{1}$ \\ ${ }^{1}$ Vologda State University, Institute of civil engineering, 160000 Vologda Lenina st. 15, Russia \\ ${ }^{2}$ Kazan State Power Engineering University, Kazan, Russia
}

\begin{abstract}
Energy conservation is a priority for most of the nation states. Its relevance in modern world energy industry is growing every year. This problem acquires particular importance when a country is characterized by a lack of fuel and energy resources or adverse climatic conditions. The most effective way to reduce heat losses from heat network pipelines to environment is the use of heat insulation. This paper presents the results of application heat-insulating paint on the surface of main pipeline. The infrared thermometry devices (pyrometer and thermal imager) were used to evaluate the energy efficiency of modern high-tech insulation. The thermograms from thermal imager and the readings from pyrometer were analyzed, it was established that the absolute difference in temperatures of an isolated pipeline section and an unpainted section are $5-10^{\circ} \mathrm{C}$. The studies have also shown that when a $250 \times 6$ pipeline is coated with a 1 $\mathrm{mm}$ thick heat-insulating paint, it will save $126.1 \mathrm{~m} 3$ of natural gas per 1 running meter per year. In monetary terms it will be approximately 610 rubles or about $\$ 9$ (for the first half of 2020). The payback period of this energy-saving measure should not exceed six months. Increasing the thickness of liquid heat insulation layer is not economically feasible. The equivalent fuel economy is approximately $65 \%$ when the heat-insulating paint is of $1 \mathrm{~mm}$ thickness, and it will increase by only $8 \%$ for a thickness of $1.5 \mathrm{~mm}$.
\end{abstract}

\section{Introduction}

The existing regulations of the Russian Federation enact to use special materials as heat insulation for pipelines. For pipelines with temperature of substances contained in them in the range from 20 to $300{ }^{\circ} \mathrm{C}$, for all laying methods, except for channelless, one should use heatinsulating materials and products with density of not more than $200 \mathrm{~kg} / \mathrm{m} 3$, coefficient of thermal conductivity in dry state not more than $0.06 \mathrm{~W} /(\mathrm{m} \bullet \mathrm{K})$ at an average temperature of $25^{\circ} \mathrm{C}$. More than 30 types of heat insulation materials meet these requirements, including reinforced concrete, bitumen perlite, gas silicate, polyurethane foam and others. Due to wide market of offers and high competition, modern heat insulation materials should posses not only good heat insulation properties, but also should be characterized by incombustibility, water repellency, sound insulation, long service life, ease of installation, sanitariness, corrosion protection, wide temperature range of application $[1,2]$.

The main type of insulation used in Russia is mineral wool products, whose share in the total volume of production and consumption is more than $65 \%$. Glass wool materials ac-count for $8 \%$, expanded polystyrene and other foams account for $20 \%$. The share of heatinsulating cellular concrete in the total volume of produced heat insulation materials does not exceed 3\%, the share of expanded perlite, vermiculite and products based on them does not exceed 2-3\% (for expanded product). The structure of production volume of heat insulation in Russia is close to that of the advanced world countries, where fibrous heat insulation also account for $60-80 \%$ of the total output of heat-insulating materials $[3,4]$.

Currently, heat-insulating paint is actively used in practice, the thickness of which on the surface of heatconducting material can be from 1.5 to $3.5 \mathrm{~m}$. Its popularity is explained by ultra-low thermal conductivity $\lambda$ (Figure 1), high adhesion to metal, ease of application to pipeline surface, short payback period (up to two years). The low thermal conductivity of ultra-thin liquid heat insulation is based on the properties of discharged gas contained in various types of substance (ceramic, silicone) microspheres with a diameter up to $100 \mathrm{I}$. Aside from low coefficient of thermal conductivity, it also have high heat-reflecting characteristics $[5,6]$.

Due to its high heat insulation qualities, liquid insulation has found its wide application in construction and heat power engineering. The studies of ultra-thin liquid-ceramic heat insulation on pipelines of heating networks showed that, for a given coefficient of thermal conductivity, heat-insulating paint is the most energyefficient heat-insulating material. For example, when Nobasil LSP liquid heat insulation of $0.4 \mathrm{~mm}$ thickness is used as heat insulation for a tank with hightemperature pitch, the heat losses reduce by a factor of 25 , compared to that of non-insulated tank. When

Corresponding author: pavlov kaftgv@mail.ru 
TEMP-COAT is used, the heat losses are reduced by a factor of 28. The payback period of the energy-saving measures for the project will be 0.22 of a whole year (about three months).

It is known that capital investments aimed at production and transportation of thermal energy from a heat source to the final consumer are directly related to the amount of fuel consumed for heating needs. For Russia, this issue is particularly acute, due to the harsh climatic conditions in which most of the country is located. According to the Ministry of Regional Development of the Russian Federation, the average cost of heating residential buildings in Russia is five to seven times higher that for Germany and other countries of the European Union. However, now Russia, being one of the leading world countries in energy reserves, is far below the economically developed countries while concerning the rational use of fuel and energy resources. The purpose of this work is to assess the energy efficiency of the use of modern high-tech insulation using the example of heat-insulating paint com-pared to that of traditional heat-insulating materials. using the thermal imager, processing of thermal images, their qualitative and quantitative analysis were carried out according to methods described in textbook [7].

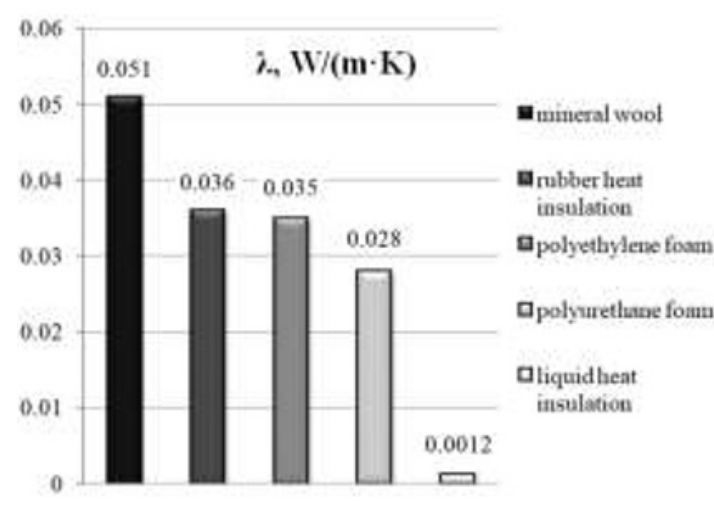

Fig. 1. Thermal conductivity of heat insulation materials of pipelines.
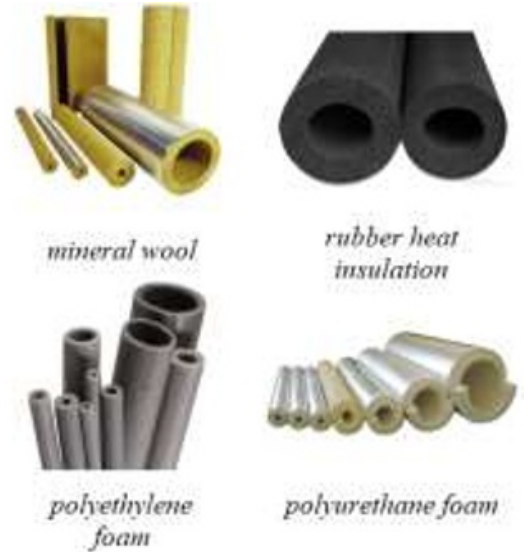
foam

\section{Materials and methods}

Consider the results of application of liquid heat insulation by the example of insulation the supply main pipeline (steel of St3 grade, $250 \times 6$ ) of the district heating system (nominal thermal power of the boiler house is 18 $\mathrm{Gcal} / \mathrm{h}$ ). The Teplomett Standard heat insulation paint was used as a heat insulation coating with the declared coefficient of thermal conductivity $\lambda_{\text {ins }}=0.003 \mathrm{~W} /(\mathrm{m} \cdot \mathrm{K})$.

Figure 2 shows the district heating boiler room (a); the pipeline section, on which a layer of heat insulation paint of variable thickness is applied (b); and the layout of heat insulation along the pipeline length (c).

The quality control of heat insulation on the surface of examined pipeline was carried out in a nondestructive way. The devices for non-contact temperature measurements were used: the Testo 845 laser infrared thermometer, and the Testo 875-2 thermal imager. Ther-mography of the object of thermal control

\section{Results and discussion}

Table 1 shows temperatures of pipeline surface measured using the Testo 845 infrared thermometer, the sections numbers are shown in Figure 2.

Table 1. Averaged surface temperature of the main pipeline

\begin{tabular}{|c|c|c|c|c|}
\hline \multirow{2}{*}{} & \multicolumn{4}{|c|}{ The number of pipeline section (Figure 2) } \\
\cline { 2 - 5 } & №1 & №2 & №3 & №4 \\
\hline$t,{ }^{\circ} \mathrm{C}$ & 68.4 & 53.2 & 59.8 & 61.0 \\
\hline
\end{tabular}

According to the heating and domestic temperature schedule of boiler room, the temperature of network water in supply and return pipelines of the centralized heat supply system at the time of heat measurements were $\tau_{1}=77{ }^{\circ} \mathrm{C}$ and $\tau_{2}=55^{\circ} \mathrm{C}$, respectively, for the outdoor temperature $t_{\text {out }}=0^{\circ} \mathrm{C}$. The internal air temperature in the boiler room was $t_{\text {in }}=24^{\circ} \mathrm{C}$. 


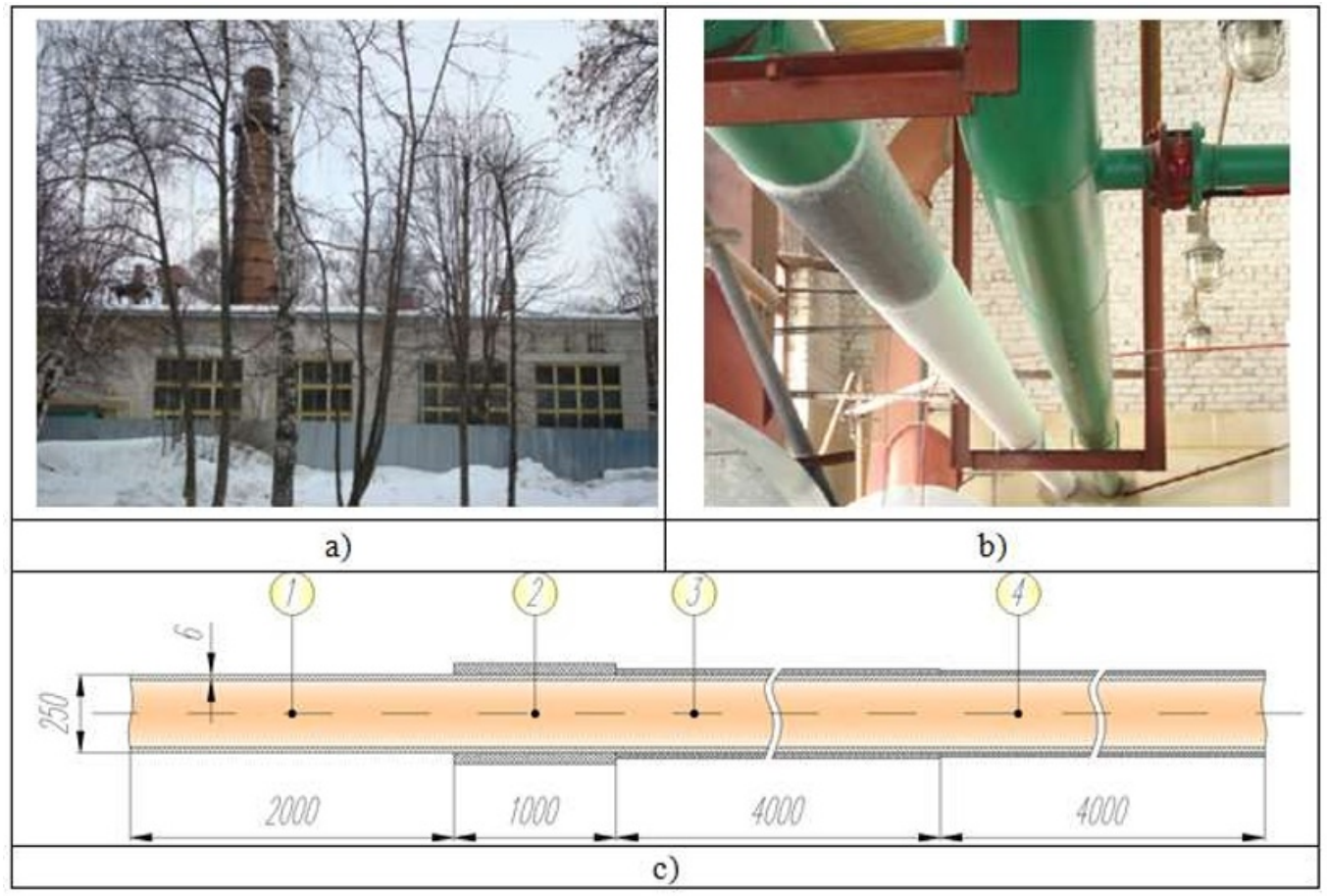

Fig. 2. a) The district heating boiler room in Vologda, Russia; b) the main pipeline; c) the layout of heat insulation along the pipeline length: 1 - unpainted pipeline; 2 - painted pipeline, $\delta_{\text {ins }}=2.2 \mathrm{~mm} ; 3$ - the same, $\delta_{\text {ins }}=1.8 \mathrm{~mm} ; 4-$ the same, $\delta_{\text {ins }}=1.5$ $\mathrm{mm}$.

The linear heat loss to environment from an isolated pipeline can be calculated using the heat transfer equation:

$$
q_{l}=\frac{\pi\left(\tau_{1}-t_{\text {int }}\right)}{\frac{1}{\alpha_{1} d_{1}}+\frac{1}{2 \lambda} \ln \frac{d_{2}}{d_{1}}+\frac{1}{2 \lambda_{\text {ins }}} \ln \frac{d_{\text {ins }}}{d_{2}}+\frac{1}{\alpha_{2} d_{\text {ins }}}}
$$

where $\alpha_{1}$ and $\alpha_{2}$ are the coefficients of convective heat exchange (heat transfer), which were calculated based on the theory of similarity and dimensionless numbers (criteria), they are equal to 5232 and $4.77 \mathrm{~W} /\left(\mathrm{m}^{2} \cdot \mathrm{K}\right)$, respectively; $\lambda$ is the coefficient of thermal conductivity of steel, for $\mathrm{St} 3$ grade it is equal to $50.2 \mathrm{~W} /(\mathrm{m} \cdot \mathrm{K}) ; d_{1}$ and $d_{2}$ are the inner and outer diameters of steel pipeline, respectively, $\mathrm{m} ; d_{\text {ins }}=d_{2}+2 \delta_{\text {ins }}$ is the outer diameter of heat insulation (heat insulation paint), $\mathrm{m}$.

The results of solving the heat transfer equation (1) were used to construct the plot showing relationship between linear heat loss to the environment and the thickness of heat insulation layer (Figure 2).

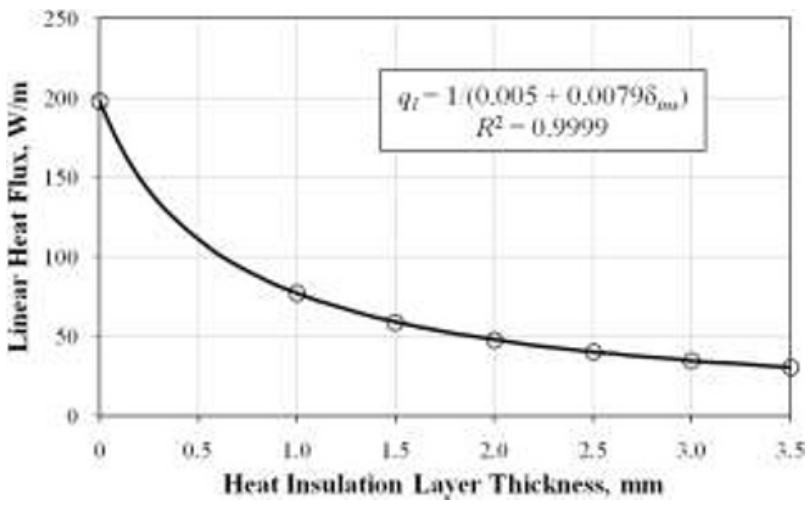

Fig. 3. Relationship between linear heat flux and the thickness of heat insulation layer.

Figure 3 shows that under the considered conditions a layer of heat-insulating paint with a thickness of allows reducing the heat loss to the environment by about $60 \%$.

Table 2 presents the results of thermal imaging of the examined pipeline with tempera-ture markers (Figure 2).

Thermal imaging gives a more complete picture of temperature state of a thermal control object than point pyrometry by infrared thermometer. For example, frame 1 clearly shows how the surface temperature of pipeline changes before and after heat insulation. Analyzing the temperature field of pipeline in frames 2,3 , and 4 , we can conclude that heat insulation has an uneven coating thickness. At the points of thermogram where the temperature is higher, the layer of heat insulation paint is smaller and vice versa. Despite the conclusions made, the readings obtained by the Testo 875-2 thermal imager are generally comparable with the results of infrared diagnostics by the Testo 845 pyrometer. The absolute difference in temperatures of an isolated pipeline section 
Table 2. Thermographic studies of the examined pipeline.

\begin{tabular}{|c|c|c|c|}
\hline $\begin{array}{l}\text { Frame } \\
\text { number }\end{array}$ & Photograph & Thermal image (thermogram) & Description \\
\hline 1. & & $\boldsymbol{y}$ & $\begin{array}{l}\text { M1: } 69.3^{\circ} \mathrm{C} \\
\text { M2: } 56.3^{\circ} \mathrm{C}\end{array}$ \\
\hline 2. & & & $\begin{array}{l}\text { M1: } 60.1^{\circ} \mathrm{C} \\
\text { M2: } 66.7^{\circ} \mathrm{C}\end{array}$ \\
\hline 3. & & & $\begin{array}{l}\text { M1: } 59.4^{\circ} \mathrm{C} \\
\text { M2: } 63.7^{\circ} \mathrm{C}\end{array}$ \\
\hline 4. & & & $\begin{array}{l}\text { M1: } 60.3^{\circ} \mathrm{C} \\
\text { M2: } 62.2^{\circ} \mathrm{C} \\
\text { M3: } 64.7^{\circ} \mathrm{C}\end{array}$ \\
\hline
\end{tabular}

and an unpainted section are in the range 5-10 ${ }^{\circ} \mathrm{C}$. It should also be noted that for this object of thermal control the results of non-contact and contact (using the TK-5 thermometer) thermometry diverge on average on $8-12{ }^{\circ} \mathrm{C}$. The readings of the contact thermometer turned out to be less than the values obtained by infrared measuring devices. This is confirmed by tests on liquid heat insulation of the Teplomett Standard brand on the surface of hot water supply boiler. These tests were carried out by the energy audit company CKT CJSC in Novosibirsk (Russia) using the SDS HotFind-D thermal imager and the IT-5-T Pt100-2 surface temperature meter, and showed that the deviation in temperatures was also approximately $8-10{ }^{\circ} \mathrm{C}$. The question on reasons for discrepancy in temperature readings obtained on the surface of the studied object of thermal control using non-contact and contact thermometry remains open.

Tests of liquid heat insulation on the surface of main pipeline were carried out in a closed room of boiler house (Figure 2), where the temperature of internal air is much higher than the outdoor air temperature registered during the heating season. However, even under such conditions, there is a possibility to achieve substantial savings in fuel and energy resources, which is clearly confirmed by the graph presented in Figure 3.

Figure 4 presents a histogram of annual consumption of equivalent fuel as a function of thickness of heatinsulating paint. The paint covers the surface of a $250 \times 6$ steel feed pipeline, the considered length is a running meter. The pipeline is air laying in Vologda (Russia). The parameters of boiler house are as follows: heating and domestic temperature schedule; design temperatures of network water $\tau_{1} / \tau_{2}=130 / 70^{\circ} \mathrm{C}$; break point of temperature graph $\tau_{1}^{\prime}=70{ }^{\circ} \mathrm{C}$ at outdoor temperature $t_{\text {out }}^{\prime}=-0.925^{\circ} \mathrm{C}$. 


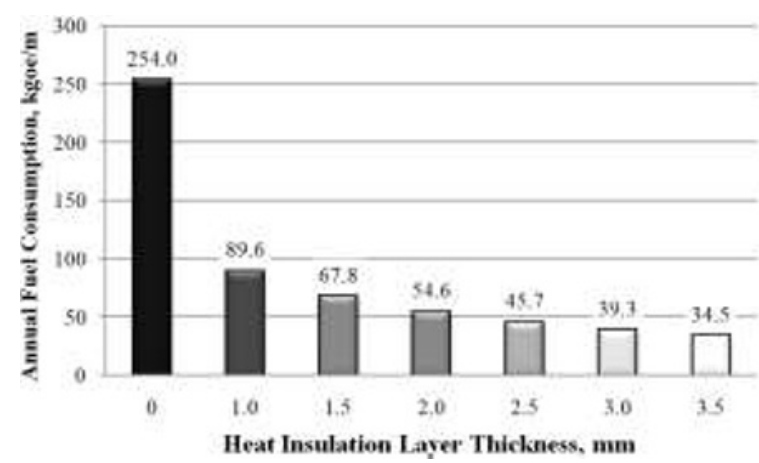

Fig. 4. Annual specific consumption of equivalent fuel.

\section{Conclusions}

The presented study shows that the annual economic benefit of application of liquid heat insulation is as obvious as reduction in the cost of fuel and energy resources for production of thermal energy (Figure 4). For example, heat insulation of a pipeline with a standard size of $250 \times 6$ by heat-insulating paint with a 1 $\mathrm{mm}$ layer thickness will save $126.1 \mathrm{~m}^{3}$ of natural gas from 1 running meter of pipeline per year. In monetary terms it will be approximately 610 rubles or about $\$ 9$ (for the first half of 2020 for the conditions of Vologda, Russia). As calculations showed, a significant economic effect can be achieved for a minimum thickness of heat insulation. For a thickness of heat-insulating paint of $\delta_{\text {ins }}=1 \mathrm{~mm}$, the economy of equivalent fuel is approximately $65 \%$, for a thickness of $\delta_{\text {ins }}=1.5 \mathrm{~mm}$ it will increase by only $8 \%$. In any case, for the declared coefficient of material thermal conductivity and the current cost of heat-insulating paint, the payback period of energy-saving measure to heat the pipelines of the district heating system should not exceed six months, which is quite cost-effective for the conditions of the Russian Federation.

\section{References}

[1] J. Zhao, G. Wang, Ch. Wang, Ch. B. Park, Ultra-lightweight, super thermal-insulation and strong PP/CNT microcellular foams, Composites Science and Technology 191, 108084 (2020).

[2] E.G. de Moraes, L. Sangiacomo, N.P. Stochero, S. Arcaro, L.R. Barbosa, A. Lenzi, C. Siligardi, A.P. Novaes de Oliveira, Innovative thermal and acoustic insulation foam by using recycled ceramic shell and expandable styrofoam (EPS) wastes, Waste Management 89, 336-344 (2019).

[3] B. Kiss, Cl.G. Manchon, L. Neij, The role of policy instruments in supporting the development of mineral wool insulation in Germany, Sweden and the United Kingdom, Journal of Cleaner Production 48, 187199 (2013).

[4] St. Lang, M. Gerschitzka, D. Bauer, H. Drück, Thermal Conductivity of Vacuum Insulation Materials for Thermal Energy Stores in Solar Thermal Systems, Energy Procedia 91, 172-181 (2016).
[5] D. Bozsaky, Laboratory Tests with Liquid Nano-ceramic Heat insulation Coating, Procedia Engineering 123, 68-75 (2015).

[6] B. Abu-Jdayil, A.-H. Mourad, W. Hittini, M. Hassan, S. Hameedi, Traditional, state-of-the-art and renewable thermal building insulation materials: An overview, Construction and Building Materials 214, 709735 (2019).

[7] A.A. Sinitsyn, D.F. Karpov, M.V. Pavlov, Basic Thermal Imaging Diagnostics of Heat-Consuming Construction Facilities (VoSU, 160, 2014). 